\title{
A proposed Framework for Software Process Improvement: Extending CMMI-DEV model Using Six Sigma and Quality Function Deployment Techniques
}

\author{
Abdel Nasser H. Zaied \\ Former Dean, College of Computers and Informatics, Zagazig University, Egypt \\ nasserhr@zu.edu.eg, nasserhr@gmail.com \\ Khalid A. El-Drandaly \\ Dean, College of Computers and Informatics, Zagazig University, Egypt \\ khalid_eldrandaly@zu.edu.eg, khalid_eldrandaly@yahoo.com \\ Al-Shaimaa A. Tantawy \\ Lecturer, Department of information systems \\ College of Computers and Informatics, Zagazig University, Egypt \\ Alshaimaa_Tantawy@zu.edu.eg, Alshaimaa_Tantawy@yahoo.com
}

\begin{abstract}
Software Process Improvement (SPI) has become the key to the survival of many software development organizations. Many international SPI models/standards, such as; ISO, Capability Maturity Model Integrated (CMMI), SPICE, Trillium ...etc, are developed for SPI. Numerous software development companies have chosen to utilize CMMI to access and improve their current software development process, because CMMI is one of the most widespread and acknowledged SPI models. Unfortunately, CMMI does not provide a systematic way of determining how to improve the process. That is, CMMI defines "what to do" but leaving "how to do it" to organizations. Thus, it is desirable to have a means to guide the companies in the development of action plans and appropriate tools for SPI. These actions should be based on the software process requirements from relevant sources. Therefore, this research proposes a SPI-CMMI framework that provides an overall process improvement strategy to be implemented in any software development organization more effectively and comprehensively. The proposed model based on applying assessment and improvement procedures through adopting the CMMI-DEV 1.3 model using six sigma approach and Quality Function Deployment (QFD) technique.
\end{abstract}

Index Terms - CMMI-DEV model, Quality Function Deployment, Six Sigma, Software Process Assessment, Software Process Improvement.

\section{Introduction}

Nowadays the software market is expanding, and the clients are requesting software products and services which are better, faster, and cheaper. High rates of software failure, rework and cost of poor quality consume a large share of software resources. Evaluating software quality is largely dependent on the quality of the development processes that used to create it. That is why software organizations are obligated to identify and improve their software development processes.

Therefore, Software Process Improvement (SPI) can be defined as a methodical procedure or a scientific technique to improve the performance of an existing process system through changing the current processes or updating new processes to correct or avoid problems identified in the old process system by means of a process assessment [1]. SPI efforts are systematically justified by the endless quest of achieving competitive advantage in customer satisfaction, business profitability, market share, product and service quality, cost reduction, cycle time reduction, ... etc. [2].

Implementing the improvement process depends on the results that come from the assessment process which determine strength, weakness, problems, and where the organization should start the improvement. Thus, Software Process Assessment (SPA) can be considered as a technical approach or a systematic procedure to investigate the existence, adequacy, and performance of an implemented process system against a model, 
standard, or benchmark [1]. Figure 1 illustrates the SPI process steps and the relationships between the SPA and SPI. Several models, methodologies and techniques are used to improve process such as; Total Quality Management (TQM), CMMI, ISO/IEC 9001, Software Process Improvement and Capability dEtermination (SPICE), Six Sigma approach, Bootstrap methodology, Trillium model ...etc.

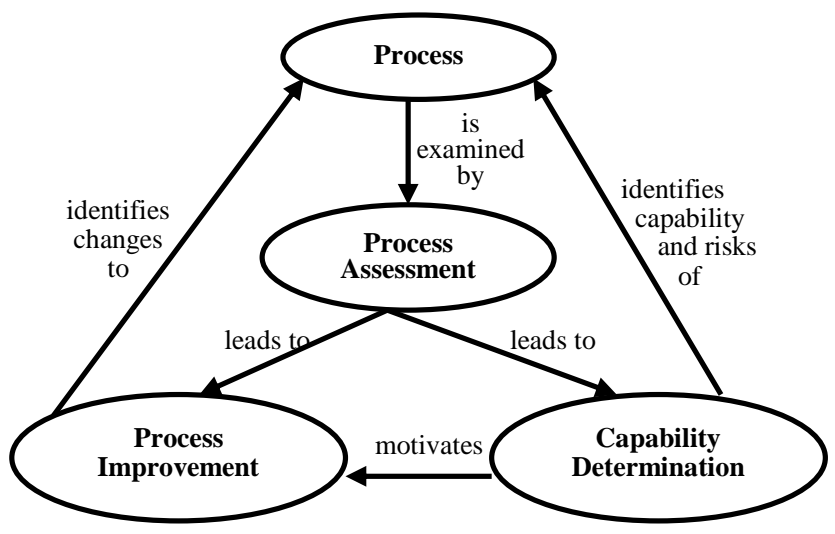

Fig 1: Software process improvement framework [3]

Some of the approaches, such as ISO 9001 are not software specific; they define general requirements for an organization and can be used at any company. Others, such as SPICE, have been derived from a software specific approach to improve specific processes. Some are created to improve development processes, others focus on services, and again others are related to processes such as software testing or resource management [4].

Therefore, this research aims at proposing a SPI-CMMI framework by integrating the CMMI-DEV model with the Six Sigma approach (DMAIC methodology, statistical tools, and metrics) and the QFD technique to perform the comprehensive improvement procedure in the software development enterprises.

The remainder of this paper is organized as follows. Section 2 illustrates the CMMI-DEV 1.3 model, whereas, section 3 presents the problem definition in this study. Section 4 presents the literature survey and section 5 explains the Six Sigma approach. Section 6 presents the QFD technique, and in section 7 the proposed SPI-CMMI framework is described with its suggested phases and benefits. Conclusion and future work are given in the final section.

\section{Capability Maturity Model Integration (CMMI)}

$\mathrm{CMMI}^{\circledR}$ models are collections of best practices that help organizations to improve their processes. These models are developed by product teams with members from industry, government, and the Software Engineering Institute (SEI) at Carnegie Mellon University. CMMI for Development (CMMI-DEV) provides a comprehensive integrated set of guidelines for developing products and services.

CMMI-DEV v1.3 is a reference model that addresses development activities applied to products and services. It addresses practices that cover the product's lifecycle from conception through delivery and maintenance. The emphasis is on the work necessary to build and maintain the total product. It contains practices that cover project management, process management, systems engineering, hardware engineering, software engineering, and other supporting processes used in development and maintenance. CMMI-DEV contains 22 Process Areas (PAs) [5].

CMMI supports two approaches to process improvement called "representations". One path "the continuous representation" enables organizations to incrementally improve processes corresponding to an individual process area (or group of process areas) selected by the organization to achieve specific capability level. The continuous representation deals with the process category. The other path "the staged representation" enables organizations to improve a set of related processes by incrementally addressing successive predetermined sets of process areas to achieve "maturity levels".

Figure 2 illustrates the structures of the continuous and staged representations. The differences between the structures are subtle but significant. The staged representation uses maturity levels to characterize the overall state of the organization's processes relative to the model as a whole, whereas the continuous representation uses capability levels to characterize the state of the organization's processes relative to an individual process area.

Capability levels apply to an organization's process improvement achievement in individual process areas. Four capability levels (numbered from 0 to 3 ) will be applied to an organization's process improvement achievement across multiple process areas. These levels are a means of improving the processes corresponding to a 
given set of process areas (i.e., maturity level). The five maturity levels are numbered 1 through 5 [5].
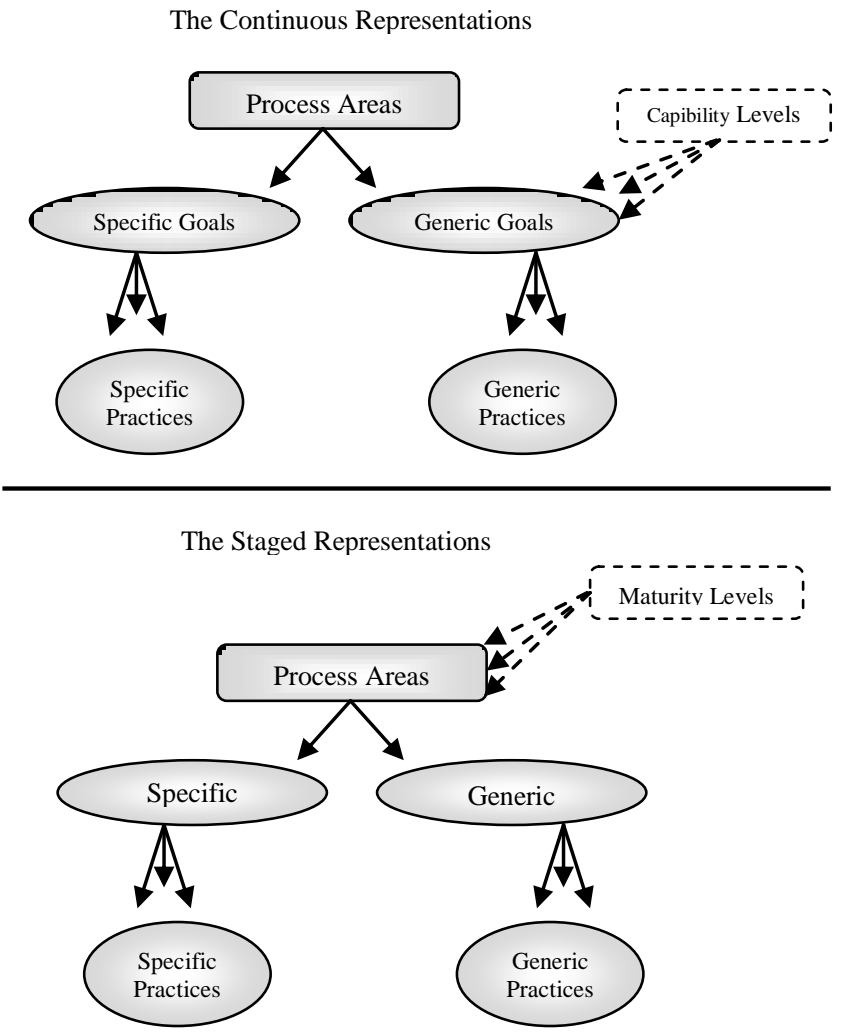

Fig 2: Structure of the Continuous and Staged Representations in the CMMIDEV 1.3 model. [5]

Table 1 compares the four capability levels to the five maturity levels. Notice that the names of two of the levels are the same in both representations (i.e., Managed and Defined). The differences are that there is no maturity level 0 ; there are no capability levels 4 and 5 ; and at level 1, the names used for capability level 1 and maturity level 1 are different.

Table 1: Comparison of Capability and Maturity Levels in the CMMI-DEV1.3 Model.

\begin{tabular}{|c|l|l|}
\hline $\begin{array}{c}\text { Level } \\
\text { Number }\end{array}$ & $\begin{array}{c}\text { Continuous } \\
\text { Representation } \\
\text { Capability Levels }\end{array}$ & $\begin{array}{c}\text { Staged } \\
\text { Representation } \\
\text { Maturity } \\
\text { Levels }\end{array}$ \\
\hline Level 0 & Incomplete & \\
\hline Level 1 & Performed & Initial \\
\hline Level 2 & Managed & Managed \\
\hline Level 3 & Defined & Defined \\
\hline Level 4 & & $\begin{array}{l}\text { Quantitatively } \\
\text { Managed }\end{array}$ \\
\hline Level 5 & & Optimizing \\
\hline
\end{tabular}

\section{Problem Definition}

Although CMMI model is one of the most widespread and acknowledged software development process definitions for improving software project performance, it has some drawbacks can be summarized in the following:

- CMMI is an "ivory tower" of theoretical concepts born of decades of research and practical application. CMMI is not and never was meant to be a replacement or a definition of anything in the real world. CMMI contains neither processes nor procedures. The CMMI practices are not steps in the organization's set of standard processes, and they are not activities that necessarily occur neatly within a specific business process [6].

- CMMI models are not processes or process descriptions. The actual processes used in an organization depend on many factors, including application domains and organization structure and size. The process areas of a CMMI model typically do not map one to one with the processes used in your organization [5].

- CMMI describes best practices but it doesn't specify how to implement those practices. Organizations have to interpret the model to meet their own applications and develop processes that will be implemented to best satisfy their business objectives. It describes what is expected in processes, not how to implement processes; definition of the how is left to each organization to decide [7].

- CMMI does not provide, in and of itself, a systematic approach of determining how to improve the process. It provides no practical information on their application. The CMMI does not provide organizations with any metrics to determine if the process improvements are effective [8].

- Two of the problems in the CMMI include interpretation and organizational decisions. The model itself was written to cover many different organizational and project situations. An ambiguous style was intentionally chosen by the authors of the CMMI to fit these many situations. This ambiguity results in the need for a lot of interpretation and decision making by the model users [9].

- Tailoring CMMI at organizational level is not easy for Small and Medium Enterprises (SMEs) as it requires hiring of skilled professionals and increases the cost of process improvement [10].

- Tully 2007 combined the CMMI problems in the following: Lack of guidance on where to start 
improvements, unique aspects of organization not accounted for, lack of Methodology, lack of Tools, and inadequate metrics [8].

- Achieving specific maturity level in CMMI model demands extensive time and high costs.

Currently, widespread research is being carried out on combining CMMI model and other SPI models or improvement approaches with the purpose of developing a single integrated solution for facilitating and accelerating the CMMI adoption and overcoming its drawbacks. These studies are discussed in the following section.

\section{Literature Survey}

Siviy and Forrester [11] provided some findings about using Six Sigma to accelerate the adoption of CMMI for optimal results such as; Six Sigma helps integrate multiple improvement approaches to create a seamless, single solution, Six Sigma adopters have a high comfort level with a variety of measurement and analysis methods, Six Sigma can accelerate the transition of CMMI, Six Sigma is effectively used at all maturity levels, Participants assert that the frameworks and toolkits of Six Sigma exemplify what CMMI high maturity requires, and CMMI-based organizational assets enable Six Sigma project-based learnings to be shared across the software and systems organizations, and thereby, enable a more effective institutionalization of Six Sigma. Siviy et al. [12] discussed the concept of integrating SPI models with each other and focused on the joint use of two models CMMI and Six-Sigma. While some models can be mapped where one model subsumes the other, CMMI and six-sigma cannot because they are different types of models. Their joint deployment is synergistic. The potential value that was added is the accelerated achievement of performance goals, accelerated achievement of CMMI adoption (as a "meta goal" toward performance), stronger foundational measurement and analysis skills to enable better quantification of results, and all the corresponding culture change that goes along with these improvements. Wilson [13] provided summary of $\mathrm{CMMI}^{\circledR}$ and Six Sigma Synergies, containing the following: Sharing infrastructure between CMMI and Six Sigma benefits both initiatives, Good measurements are essential to successful Six Sigma implementation and support CMMI goals, DMAIC and DFSS have strong ties to CMMI specific and generic practices. Huang and Han [14] presented a decision support model that assists managers in determining the priorities of the CMMI process areas for only the software organizations that adopt the continuous representation of the CMMI model.

Albeanu et al. [15] described the usage of the Six Sigma methodology for software quality assurance and how a mixed six-sigma and CMMI could be applied to increase the capability and maturity level of the software department. Siakas et al. [16] explored Six Sigma and CMMI in terms of their relationships to one another similarities and differences and how a company can blend the two for added value and argues that the Six Sigma methodology when blended with CMMI is likely to enable businesses to effectively overcome the challenges of deployment and deliver optimal results. Siviy et al. [17] abstracted the following strategies for using CMMI with Six Sigma: Implement CMMI process areas as Six Sigma projects, Use Six Sigma as the tactical engine for high capability and high maturity, Apply Six Sigma to improve or optimize an organization's improvement strategy and processes, and Integrate CMMI, Six Sigma, and all other improvement initiatives to provide a standard for the execution of every project throughout its life cycle. Tully [8] provided a guide to Six Sigma practitioners in how using Six Sigma (tools, metrics, and methodology) to meet CMMI guidelines to incrementally improve the maturity of the software development organization. Habib et al. [10] explained how SMEs can adopt CMMI by tailoring it to suit their requirements and then blending the cut-down version with Six Sigma's Define, Measure, Analyze, Improve, and Control (DMAIC) methodology to reduce the time required to attain CMMI Maturity Level 2 and 3. Sun [18] proposed SPI frameworks based on CMM or CMMI using QFD technique aiming to achieve three objectives: (1) to map process requirements, including business requirements, to CMM or CMMI, with the help of QFD; (2) to develop a method based on QFD for the integration and prioritization of requirements from multiple perspectives; and (3) to be able to prioritize SPI actions based on process requirements. Baldassarre et al. [19] proposed a theoretical harmonization process that supports organizations interested in introducing quality management and software development practices or concerned about improving those they already have. This was done with specific reference to CMMI-DEV and ISO 9001 models in the direction "ISO to CMMI-DEV', showing how Goal-Question-Metric (GQM) was used to define operational goals that address ISO 9001 statements, reusable in CMMI appraisals. Then they applied the theoretical comparison process to a real case, i.e., a Small Enterprise certified ISO 9001.

Based on the detailed study and analysis of the previous literature survey presented above, we have found that: 
- Six Sigma approach can help accelerate CMMI implementation at all levels of maturity and capability, Six Sigma strengths complement CMMI weaknesses, and CMMI strengths complement Six Sigma weaknesses [13].

- By mapping the process requirements with CMMI, QFD technique displays the benefits of satisfying requirements through process improvement. In addition, process requirements from multiple groups of stakeholders (perspectives), including the business goals, are integrated and prioritized. SPI actions are linked to these process requirements using QFD. Thus, the priorities of actions reflect the priorities of process requirements. By executing the actions with the highest priorities, the highest satisfaction level of process requirements can be achieved [18].

- Most of these studies adopt a narrow point of view or reasons for integrating CMMI with other SPI models and approaches.

- There is no complete process improvement strategy to be implemented in the software organizations.

Therefore, this research proposes a SPI-CMMI framework that provides an overall and general process improvement strategy from organization assessment to process improvement to be implemented in any software development organization aims to implement system and software process improvement more effectively and comprehensively, as illustrated in the following sections.

\section{Six Sigma Approach}

Six Sigma business improvement strategy was introduced by Motorola in the mid-1980s. The Greek symbol $\boldsymbol{\sigma}$ represents the standard deviation to measure variability from the mean or the average. From organizations perspective, variation is often the cause of defects or out-of-control processes and translates into products or services that do not meet customer needs or expectations [20].

Six Sigma approach was adopted successfully by General Electric and other large corporations in the 1990s. The key focus of all Six Sigma programs is to optimize overall business results by balancing cost, quality, features, and availability considerations for products and their production into a best business strategy. Six Sigma programs combine the application of statistical and non-statistical methods to achieve overall business improvements. In that sense, it is a more strategic and more aggressive initiative than simple improvement projects [21].

Six Sigma approach has many perspectives, such as; a business improvement strategy, a philosophy, a performance measurement, an improvement framework, a set of improvement statistical tools, and a critical mass of highly trained individuals who serve as analysts, problem solvers, and change agents ${ }^{[17]}$. It is also an organized and systematic method for strategic process improvement and new product and service development that relies on statistical methods and the scientific methodology to make dramatic reductions in customer defined defect rates ${ }^{[22]}$. In Six Sigma, the focus is on process improvement to increase capability and reduce variation [23].

The methods used in Six Sigma contain several common principles, such as data-driven, decisionmaking and project management fundamentals. Tools and Methods used in it are adaptive and iterative. Adaptive implies the fact that it can be tailored to a variety of situations and business contexts. Moreover, any given Six Sigma method can be integrated with another process or methodology as an underpinning to identify, gather, analyze, and report on critical parameters in a proactive or reactive manner. The adaptive nature of these methods also speaks to the wide array of industries and situations in which they can be applied. The iterative nature of the Six Sigma methods stems from the fact that more information on a variable or potential root cause gets revealed as the project progresses [24].

The Define Measure Analyze Improve Control methodology (DMAIC) is the classic Six Sigma problem solving process. Traditionally, the approach is to be applied to a problem with an existing, steadystate process or product and/or service offering. Design for Six Sigma (DFSS) methodology represents a portfolio of methods and tools that expands Six Sigma concepts to take a preventative approach by designing quality into a product (or process).

The DFSS methodology applies to technical design applications; it also features a unique subset of tools applicable to general business applications. DFSS methodology evolved to address the need for a redesign or new design - an innovation in response to a problem. If the process is incapable of meeting the desired customer specifications, it requires a redesign or an altogether new design to be consistent with the new desires and requests [24]. 


\section{Quality Function Deployment (QFD)}

QFD technique is best viewed as a planning tool that relates a list of delights, wants, and needs of customers to design technical functional requirements. With the application of QFD, possible relationships are explored between quality characteristics as expressed by customers and substitute quality requirements expressed in engineering terms. Since 1966, QFD has been used world-wide in nearly every industry and sector to prioritize spoken and unspoken customer needs; to translate these needs into actions and designs such as technical characteristics and specifications; and to build and deliver a quality product or service by focusing on achieving a common goal of customer satisfaction [18].

In other words, QFD technique can be considered as a procedure to assure that customer desires and requirements drive the product design and production process. Typically, a QFD system can be broken down into four inter-linked phases to fully deploy the customer needs phase by phase. In QFD, each phase's important outputs (HOWs), generated from the phase's inputs (WHATs), are converted into the next phase as its inputs (new WHATs). So, each phase can be described by a matrix of "WHATs" and "HOWs", which is easy and convenient to deal with in practice.

The four QFD sequential phases include: Phase 1 to translate customer needs into product design attributes which we will call technical measures; Phase 2 to translate important technical measures into parts characteristics; Phase 3 to translate important parts characteristics into process operations; and Phase 4 to translate key process operations into day to day production requirements [25]. Figure 3 illustrates the four phases in the QFD house schematic.

Using the QFD technique in the improvement process helps the enterprises to: translate customer requirements into specific offering specifications and Prioritize possible offering specifications and make trade-off decisions based on weighted customer requirements and ranked competitive assessment. It is a powerful prioritization tool that combines several different types of matrices into one to form a houselike structure. Sometimes referred to as a House of Quality (HOQ), this tool captures the Voice of the Customer (VOC) to identify the required quality, features, and functions needed to be deployed in a single offering [24].

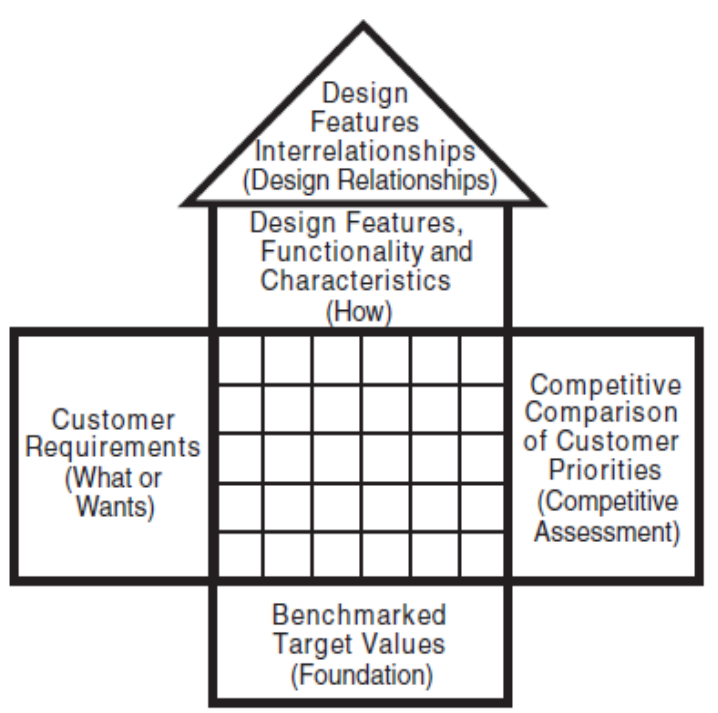

Fig 3: House Schematic of QFD phases [24]

\section{The Proposed SPI-CMMI Framework}

The proposed SPI-CMMI framework will show how to use Six Sigma methodology, tools, metrics and QFD technique to meet CMMI-DEV v1.3 guidelines, to incrementally improve the maturity of the software development organization. The proposed framework targets all companies that develop software and seeking to make improvements within their current software development processes through adopting the CMMI-DEV 1.3 model. The proposed SPI-CMMI framework contains ten consecutive phases illustrated briefly as the following.

\section{Phases of the proposed SPI-CMMI framework}

Phase-1: Organization Assessment using Six Sigma tools and metrics to evaluate the current state of the organization, through determining the capabilities, strengths, and the weaknesses to specify where the organization should start the development process. The capability of a process will affect how the process improvement professional applies the Six Sigma methodology and QFD technique for CMMI. Performing an organizational assessment using the following successive seven steps:

Step1: Determine and get together Subject Matter Experts (SMEs).

Step2: Develop a planning methodology for the improvement project.

Step3: Generate a SIPOC of the entire software development organization.

Step4: Construct the process map.

Step5: Create a process inventory document.

Step6: Determine capability levels for each process. 
Step7: Formulating strategic direction and management goals/objectives.

Phase-2: Determining Success Metrics it is very important for any process improvement effort to determine which measures should be specified to show improvement progress and benefits. An important methodology for deriving success metrics is the Goal-Question-Metric (GQM) approach and the Dashboard document to track and record the metrics. Moreover, in this phase the organization should use the ScoreCard tool. It is the main predictive tool for both in-process measures and performance results. Improvement project team should measure progress in contrast to their goals. Besides, Six Sigma provides the Data Collection Matrix that possibly will be used to plan and organize the data collection process for the improvement project.

\section{Phase-3: Requirements Elicitation and Integration} collecting the requirements from all the stakeholders, developing a method based on QFD technique and the priority assessment technique for the integration and prioritization of requirements from multiple perspectives (Customer, Business, Management, Quality ...etc.) as suggested by Sun in [18]:

1.Defining the various perspectives from the stakeholders and collecting their corresponding requirements.

2.The requirements from multiple perspectives are correlated with each other using the priority assessment technique into one single set.

Phase-4: Process Areas (PAs) Prioritization: For each of the process categories in the CMMI continuous representation (OR for each maturity level in the CMMI staged representation), the set of requirements with adjusted priorities are related to the specific PAs. The specific PAs are prioritized based on those process requirements. Thus, the PAs that achieve higher overall satisfaction of process requirements get higher importance.

Phase-5: Specific Goal Prioritization: For each prioritized process area, the set of requirements with adjusted priorities are related to the specific goals. The specific goals are prioritized based on those process requirements. Thus, the specific goals that achieve higher overall satisfaction of process requirements get higher importance.

Phase-6: Specific Practices Prioritization: involves the prioritization of Specific Practices within all PAs of a specific maturity level (Staged CMMI) or within all PAs of a specific process category (Continuous CMMI). The prioritization is carried out based on the deliverables from Phase 5. According to CMMI specifications, all these Specific Practices must be performed to reach that particular maturity level.

Phase-7: Action Plans Development and Prioritization, a set of actions and detailed activities is derived from the prioritized practices. The priorities of actions reflect the priorities of process requirements. By executing the actions with the highest priorities, the highest satisfaction level of process requirements can be achieved.

Phase-8: Action Plans and Practices Implementation: Using the appropriate Six sigma tools, methods, techniques and suggested metrics in applying the prioritized practices and action plans for each process area, to ensure much more successful implementation of the organization's CMMI specific goals and practices in accurate and fast manner.

Phase-9: CMMI Capability Levels Implementation: Process capability deals with the how well defined and managed the process is. Generic goals and practices are those activities that ensure that the process improvements identified will be effective over the long term. They should be implemented to all of the process areas within the CMMI. This phase includes suggested activities and steps within the sixsigma methodology (DMAIC).

Phase-10: Capability Levels Activities Implementation. Using the appropriate Six sigma tools, methods, techniques and suggested metrics in applying the suggested activities and steps for each capability level, to ensure much more successful implementation of the organization's CMMI-DEV generic goals and practices in precise and managed manner.

Figure 4 summarizes the successive steps will be applied in the proposed SPI-CMMI framework. Also, for more explanation Table 2 describes briefly the sequential ten phases of the proposed SPI-CMMI framework with the corresponding suggested tools, techniques and metrics which will be used in the software organization for the process assessment and improvement. 


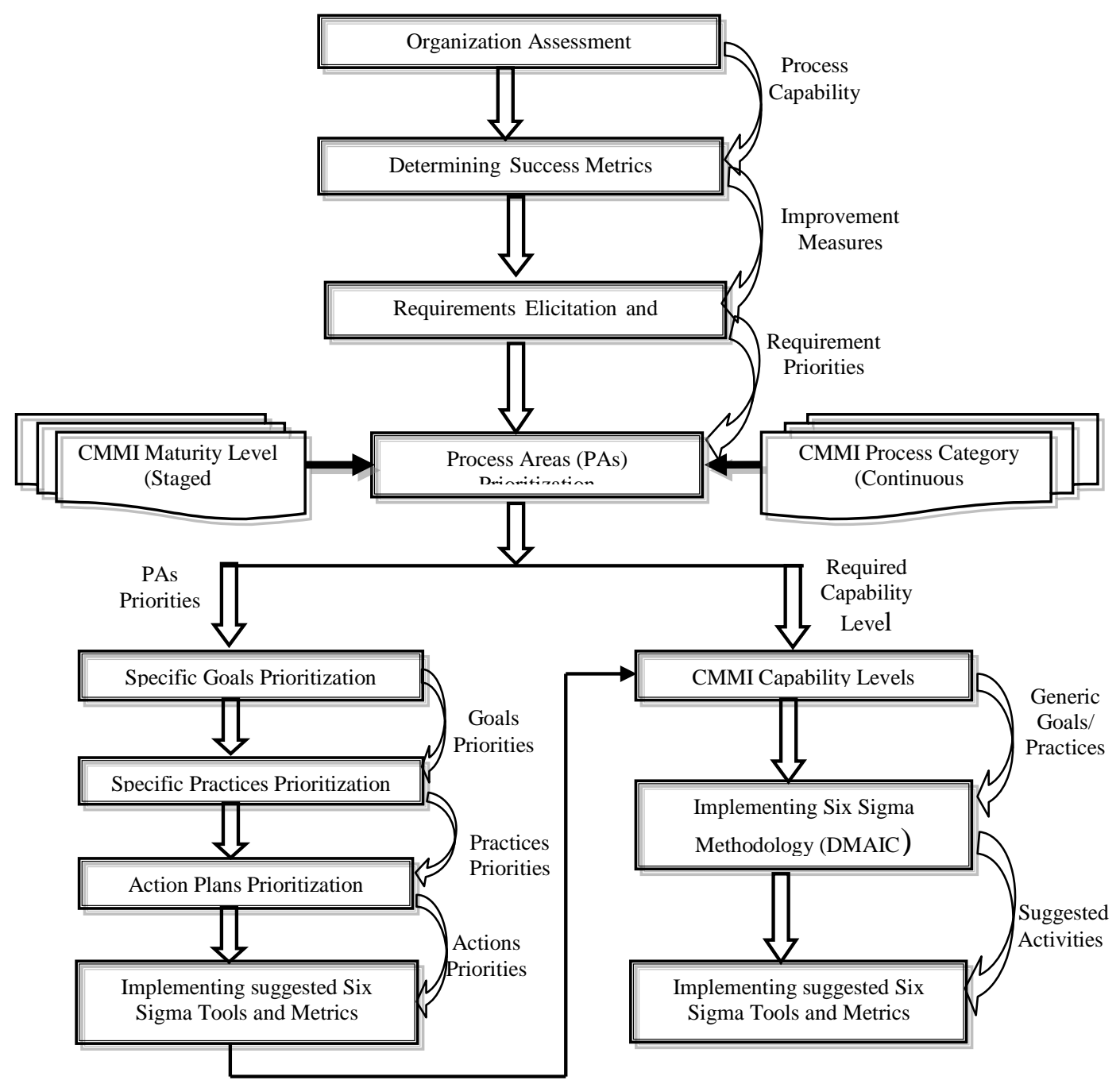

Fig 4: The successive steps of the proposed SPI-CMMI framework. 
Table 2: The ten successive Phases of the proposed SPI-CMMI framework.

\begin{tabular}{|c|c|c|}
\hline The Phase & The Brief Description & $\begin{array}{c}\text { Suggested Tools, Techniques } \\
\text { and Metrics }\end{array}$ \\
\hline $\begin{array}{l}\text { Phase-1: } \\
\text { Organization } \\
\text { Assessment }\end{array}$ & $\begin{array}{l}\text { The suggested Six sigma tools and techniques are used to evaluate the } \\
\text { current state of the organization, through determining the } \\
\text { capabilities, strengths, and the weaknesses of the development } \\
\text { processes. The phase contains seven successive steps. }\end{array}$ & $\begin{array}{l}\text {-SWOT Tool } \\
\text {-SIPOC Tool } \\
\text {-Process Map } \\
\text {-SMART Technique } \\
\text { - GOSPA Technique } \\
\text {-Process Capability Analysis }\end{array}$ \\
\hline $\begin{array}{l}\text { Phase-2: } \\
\text { Determining } \\
\text { Success } \\
\text { Metrics }\end{array}$ & $\begin{array}{l}\text { It is very important for any process improvement effort to determine } \\
\text { which measures should be specified to confirm improvement benefits } \\
\text { and monitor project progress. }\end{array}$ & $\begin{array}{l}- \text { GQM Technique } \\
- \text { CTQ Technique } \\
- \text { ScoreCards tool } \\
\text {-Dashboard Tool } \\
- \text { Data Collection Matrix } \\
\end{array}$ \\
\hline $\begin{array}{l}\text { Phase-3: } \\
\text { Requirements } \\
\text { Elicitation and } \\
\text { Integration }\end{array}$ & $\begin{array}{l}\text { Collects requirements from multiple perspectives (Customer, } \\
\text { Business, Management, Quality ...etc.), and develops a method } \\
\text { based on six sigma and QFD technique for the integration and } \\
\text { prioritization of requirements. }\end{array}$ & $\begin{array}{l}\text { - Stakeholder Analysis } \\
\text { - Brainstorming Technique } \\
\text {-Voice of Customer Gathering } \\
\text {-QFD Technique } \\
\text {-MPQP Tool } \\
\text {-Priority Assessment Technique }\end{array}$ \\
\hline $\begin{array}{l}\text { Phase-4: } \\
\text { Process Areas } \\
\text { (PAs) } \\
\text { Prioritization } \\
\end{array}$ & $\begin{array}{l}\text { The set of requirements with adjusted priorities are related to the } \\
\text { specific PAs. The specific PAs are prioritized based on those process } \\
\text { requirements. Thus, the PAs that achieve higher overall satisfaction } \\
\text { of process requirements get higher importance. }\end{array}$ & $\begin{array}{l}- \text { QFD Technique } \\
- \text { Prioritization Matrices } \\
\text {-Priority Assessment Technique }\end{array}$ \\
\hline $\begin{array}{l}\text { Phase-5: } \\
\text { Specific Goal } \\
\text { Prioritization }\end{array}$ & $\begin{array}{l}\text { For each prioritized PA, specific goals are prioritized based on those } \\
\text { process requirements. Thus, the specific goals that achieve higher } \\
\text { overall satisfaction of process requirements get higher importance. }\end{array}$ & $\begin{array}{l}- \text { QFD Technique } \\
\text {-Prioritization Matrices } \\
\text {-Priority Assessment Technique }\end{array}$ \\
\hline $\begin{array}{l}\text { Phase-6: } \\
\text { Specific } \\
\text { Practices } \\
\text { Prioritization } \\
\end{array}$ & $\begin{array}{l}\text { This phase involves the prioritization of specific practices within all } \\
\text { PAs of a specific maturity level (Staged CMMI) or within all PAs of } \\
\text { a specific process category (Continuous CMMI). }\end{array}$ & $\begin{array}{l}- \text { QFD Technique } \\
- \text { Prioritization Matrices } \\
\bullet \text { Priority Assessment Technique }\end{array}$ \\
\hline $\begin{array}{l}\text { Phase-7: } \\
\text { Action Plans } \\
\text { Development/ } \\
\text { Prioritization }\end{array}$ & $\begin{array}{l}\text { A set of actions is derived from the prioritized practices. The } \\
\text { priorities of actions reflect the priorities of process requirements. By } \\
\text { executing the actions with the highest priorities, the highest } \\
\text { satisfaction level of process requirements can be achieved. }\end{array}$ & $\begin{array}{l}\text {-QFD Technique } \\
\text {-Prioritization Matrices } \\
\text {-Priority Assessment Technique } \\
\text { - House of Quality (HOQ) }\end{array}$ \\
\hline $\begin{array}{l}\text { Phase-8: } \\
\text { Action Plans/ } \\
\text { Practices } \\
\text { Implementatio } \\
\mathrm{n}\end{array}$ & $\begin{array}{l}\text { Using the appropriate Six Sigma tools, methods, techniques and } \\
\text { suggested metrics in applying the prioritized practices and action } \\
\text { plans for each process area, in order to ensure much more successful } \\
\text { implementation of the organization's CMMI specific goals and } \\
\text { practices in accurate and fast manner. }\end{array}$ & $\begin{array}{l}\text { - A group of appropriate Six } \\
\text { Sigma techniques, methods, } \\
\text { and suggested metrics for each } \\
\text { phase of action and specific } \\
\text { practice in specific process } \\
\text { area. }\end{array}$ \\
\hline $\begin{array}{l}\text { Phase-9: } \\
\text { CMMI } \\
\text { Capability } \\
\text { Levels } \\
\text { Implementatio } \\
\mathrm{n} \\
\end{array}$ & $\begin{array}{l}\text { Generic goals and practices for each capability level should be } \\
\text { implemented to all of the process areas within CMMI. This phase } \\
\text { includes suggested activities, actions and steps within the six-sigma } \\
\text { methodology (DMAIC). }\end{array}$ & $\begin{array}{l}- \text { Applying Six Sigma } \\
\text { methodology (DMAIC) } \\
\text { [Define -Measure - Analyze - } \\
\text { Improve - Control] }\end{array}$ \\
\hline $\begin{array}{l}\text { Phase-10: } \\
\text { Capability } \\
\text { Levels } \\
\text { Activities } \\
\text { Implementatio } \\
\mathrm{n} \\
\end{array}$ & $\begin{array}{l}\text { Using the appropriate Six Sigma tools, methods, techniques and } \\
\text { suggested metrics in applying the suggested activities and steps for } \\
\text { each capability level, in order to ensure much more successful } \\
\text { implementation of the organization's CMMI generic goals and } \\
\text { practices in precise and managed manner. }\end{array}$ & $\begin{array}{l}\text { - A group of appropriate Six } \\
\text { Sigma tools, methods, } \\
\text { techniques and suggested } \\
\text { metrics for each phase of } \\
\text { DMAIC activity and generic } \\
\text { practices. }\end{array}$ \\
\hline
\end{tabular}




\section{The benefits of the proposed SPI framework}

The proposed SPI-CMMI framework in this research provides an overall systematic methodology for process improvement strategy to be implemented in any software development organization aims to implement system and software process improvement more effectively and comprehensively. It based on integrating Six Sigma approach, and QFD technique with CMMI-DEV model for increasing the likelihood and accelerating of its adoption and enhancing its capabilities and efficiency. CMMI is chosen in this framework because of its popularity in the industry, as it is being adopted worldwide and proven effectiveness. CMMs, for many years, has shown positive results in terms of both tangible benefits such as cost, schedule, product quality, productivity, and amount of rework and intangible benefits such as improvements in the quality of work life, organization communications; organization learning and efficiencies; the ability to attract, retain, and develop software professionals; and the coherency of its organization culture. Similarly, SEI also reported the effectiveness of CMMI by comparing data from 35 organizations. Tangible benefits such as; cost, schedule, productivity, quality, customer satisfaction, and return on investment (ROI) were obvious [18]. One of the most important aspects of any process improvement effort is the measure taken to show improvement. Many organizations blindly select a CMMI maturity level they would like to achieve but fail to show any benefits from their improvement of CMMI based maturity goals when the senior management decides to cut costs. Therefore, a methodology, like Six Sigma's DMAIC, which requires the use of data to show objective evidence of improvements, buttresses the adoption of CMMI. It ensures that the focus of all improvements is on providing demonstrable and quantifiable results that translate into a monetary value, justifying the improvement efforts. Therefore, using the six-sigma's metrics in this framework is critical for the following reasons:

(1) Show progress towards organization goals,

(2) Show return-on-investment (ROI), and

(3) Feedback for future goals [8]

Also, there are three original contributions in the proposed SPI-CMMI framework, all with the help of QFD technique [18]:

- First, business, management, customer and other requirements within an organization are mapped to process areas and practices in CMMI-DEV. A connection is established so that the organization can see clearly how CMMI-DEV helps with its business.
- Second, business needs and software process requirements from various perspectives are integrated and prioritized.

- Third, QFD technique is used to help transforming requirements of the organization into process actions through CMMI-DEV model. It will be shown that this directly results in the improvement of the organization process.

\section{Conclusion}

In this paper a proposed SPI-CMMI framework is constructed to provide an overall and general systematic methodology for process improvement strategy to be implemented in software development organizations that aim to implement system and software process improvement more effectively and comprehensively. It based on integrating Six Sigma approach, and QFD technique with CMMI-DEV v1.3 model for increasing the likelihood and accelerating of its adoption and enhancing its capabilities and efficiency. First, the proposed SPI framework will determine the actual current state of the software organization by the assessment process using the appropriate Six Sigma tools. Then the proposed SPICMMI framework will help the software organizations achieve both the maturity and capability levels in the CMMI-DEV model. The framework provides the software company with the detailed successive steps, tasks and activities to be performed in each process area with the appropriate tools to be implemented also. The future work of this research will be conducting the validation questionnaire with the software development companies and the implementation of the proposed SPI-CMMI framework to a real case study for proving its validation, proficiency and checking its competence.

\section{References}

[1] Dumke, R., Braungarten, R., Blazey, M., Hegewald, H., Reitz, D., and Richter, K., "Software Process Measurement and Control", Faculty of Computer Science, Otto von Guericke University Magdeburg, (2006).

[2] Ferreira, A., and Machado, R., Software Process Improvement in Multi-model Environments, Fourth International Conference on Software Engineering Advances, IEEE Computer Society, DOI 10.1109/ICSEA. 2009, 80: 512517.

[3] SPICE, "ISO/IEC Software Process Assessment", SPICE Working Draft V1.00. 1995.

[4] Kelemen, Z. D., Kusters R., and Trienekens J., Identifying criteria for multi-model software process improvement solutions - based on a review of current problems and initiatives, Journal of Software Maintenance and Evolution: Research and Practice, 2012, 24: 895-909.

[5] Carnegie Mellon University-Software Engineering Institute CMU-SEI, "CMMI ${ }^{\circledR}$ for Development, Version 1.3", 
CMU/SEI-2010-TR-033， ESC-TR-2010-033， 2010, Pittsburgh, USA.

[6] Carnegie Mellon University-Software Engineering Institute CMU-SEI, CMMI ${ }^{\circledR}$ or Agile: Why Not Embrace Both, CMU/SEI-2008-TN-003, Pittsburgh, USA.

[7] Mutafelija, B., and Stromberg, H., Process Improvement with $\mathrm{CMMI}^{\circledR}$ v1.2 and ISO Standards, CRC Press LLC, Auerbach Publications, Taylor \& Francis Group, 2009.

[8] Tully, E. M., A guide for utilizing Six Sigma in achieving CMMI maturity goals, Master Thesis, ProQuest Dissertations and Theses (PQDT); Fall, 2007.

[9] Kulpa, K. M., and Johnson, A. K., Interpreting the CMMI ${ }^{\circledR}$ : a process improvement approach, $2^{\text {nd }}$ ed., CRC Press LLC, Auerbach Publications, Taylor \& Francis Group, 2008.

[10] Habib, M., Ahmed, S. ; Rehmat, A. ; Khan, M.J. ; Shamail, S., Blending six sigma and CMMI - an approach to accelerate process improvement in SMEs, Multitopic Conference. INMIC. IEEE International, 2008. 4770546, 386-391.

[11] Siviy, J. M., and Forrester, E. C., Using Six Sigma to Accelerate the Adoption of CMMI for Optimal Results, Carnegie Mellon University- Software Engineering Institute, Pittsburgh, PA, 2004, 15213-3890.

[12] Siviy, J. M., Penn, M. L., and Harper, E., Relationships between $\mathrm{CMMI}^{\circledR}$ and Six Sigma, Carnegie Mellon University- Software Engineering Institute, CMU/SEI-2005TN-005, Pittsburgh.

[13] Wilson, D., CMMI ${ }^{\circledR}$ and Six Sigma Synergy, SEPG, Natural SPI, Inc., 2005.

[14] Huang, S.-J.; and Han, W.-M., Selection priority of process areas based on CMMI continuous representation, Information \& Management Journal, 2006, 43: 297-307.

[15] Albeanu, G., Thyregod, P., Madsen, H., and PopentiuVladicescu, F., On Using Six Sigma Methodology for Software Quality Assurance, the sixth Annual ENBIS Conference in Wroclaw, Poland, 2006.

[16] Siakas K. V., Nisioti K. S., Voutsa E. A., Gellén M., Integrating Six Sigma with CMMI for High Quality Software, Perspectives in Software Quality, Proceeding of the $14^{\text {th }}$ Software Quality Management Conference, (SQM), April, Southampton, UK, ISBN 1-902505-76-X, The British Computer Society, 2006, 85-96.

[17] Siviy, J. M., Penn, M. L., and Stoddard, R., Achieving Success via Multi-Model Process Improvement, SEPG 2007, Carnegie Mellon University- SEI, Pittsburgh, PA, 152133890.

[18] Sun, Y., Business-Oriented Software Process Improvement based on CMM and CMMI Using QFD, Ph. D. Dissertation, Faculty of the Graduate School of the University of MissouriRolla, Computer Science, 2008.

[19] Baldassarre, M. T., Caivano, D., Pino, F. J., Piattini, M., and Visaggio, G., (2012), Harmonization of ISO/IEC 9001:2000 and CMMI-DEV: from a theoretical comparison to a real case application, Springer Science Business Media, LLC, Software Quality Journal, 2012, 20: 309-335.

[20] Marchewka, J. T., Information Technology Project Management, $2^{\text {nd }}$ ed., John Wiley \& Sons, 2006.

[21] Kenett, R. S., and Baker, E. R., Process Improvement and $\mathrm{CMMI}^{\circledR}$ for Systems and Software, CRC Press, Auerbach Publications, Taylor \& Francis Group, LLC, Boca Raton, 2010.

[22] Linderman, K., Schroeder, R.G., Zaheer, S., and Choo, A.S., Six Sigma: a goal-theoretic perspective. Journal of Operations Management, 2003, 21: 193-203.

[23] El-Haik, B., and Shaout, A., Software Design for Six Sigma: A Roadmap for Excellence, John Wiley \& Sons, Inc., Hoboken, New Jersey, 2010.
[24] Hambleton, L., Treasure chest of six sigma growth methods, tools and best practices, Prentice Hall, Pearson Education, Inc., 2008.

[25] Chan, L-K., and Wu, M-L., A systematic approach to quality function deployment with a full illustrative example, The International Journal of Management Science, Omega 2005, 33: $119-139$

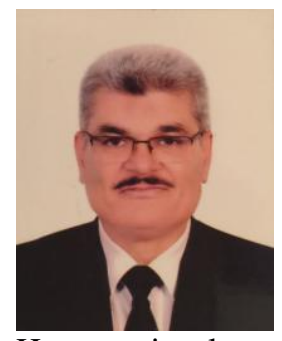

Prof. Abdel Nasser H. Zaied is a Former Dean, College of Computers and Informatics, Zagazig University, Egypt. Former Adviser to the Minister of Higher Education for Private and National Universities.

He previously worked as a Professor of Industrial Engineering, Zagazig University Egypt; an assistant professor of Technology Management, Arabian Gulf University, Bahrain; and as visiting professor at Oakland University, USA. He supervised $19 \mathrm{PhD}$ theses and $57 \mathrm{MSc}$. theses, and examined $53 \mathrm{MSc} \& 17 \mathrm{PhD}$ theses. He published 49 research papers in International and Regional Journals and 25 research papers in International and National conferences. His areas of research are: Systems Analysis and Design; Information Security; Knowledge Management; Quality Management Systems, Project Management and Electronic applications.

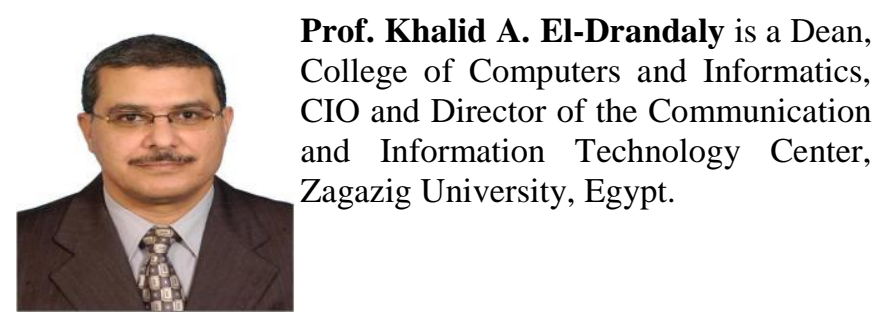

Dr. Eldrandaly is a certified GIS professional (GISP). He received his Ph.D. degree in Systems Engineering (GIS). He was a visiting scholar at Texas A\&M University, USA. His research interests include GIS, Expert Systems, SDSS, MCDM, and Intelligent Techniques in Decision Making. Dr. Eldrandaly is a member of the Egyptian Engineers Syndicate, Texas A\&M International Faculty Network, Egyptian Software Engineers Association (ESEA), GIS Certification Institute, International Society for Environmental Information Science, and Association of Computing Machinery (ACM). He also currently serves as a member in the Review Committee of the IAJIT, IJGIS, IJOPCM, ASOC, ACIT, JEI, FCT \& AJSE.

Al-Shaimaa A. Tantawy is a Lecturer of Information Systems, College of Computers and Informatics, Zagazig University, Egypt. 